\title{
Colorimetric Determination of Pectinase Activity towards Pectin in Reverse Micellar System: A Model Study for Bio-scouring of Cotton
}

\author{
Kazuya Sawada, Seishi Tokino, Mitsuo Ueda \\ Dept of Chemistry and Material Technology, Kyoto institute of technology \\ Goshokaido-cho, Matsugasaki, Sakyo-Ku, 606-0962, Japan
}

\begin{abstract}
Colorimetric determination method of D-galacturonic acid in reverse micellar solution has been investigated in order to assay pectinase catalyzed enzymatic hydrolysis of pectin in reverse micellar solution as a model study for bio-scouring of cotton in organic media. D-galacturonic acid produced by the hydrolysis of pectin could be detected by a specific condensation reaction with naphthoresorcinol. Condensation products showed clear blue color in reverse micellar solution that can be monitored by a spectroscopic determination method. Apparent rate of hydrolysis of pectin with pectinase enzyme in the reverse micellar solution obtained by the spectroscopic determination method was found to be slower than that in aqueous media, whereas the apparent rate of removal of the pectin from cotton fabrics by the pectinase assisted bio-scouring process in reverse micellar system was appreciably faster than that in aqueous media. The above difference between the results from the model study and from the practical bio-souring study would be attributed to the influence of cotton wax exist on actual cotton substrate that acts as gluing material for pectin and inhibit hydrolysis of pectic substances. Quick removal of cotton wax must be taken into account in the bio-scouring process to obtain effective scouring results.
\end{abstract}

\section{Introduction}

Pectic substance is one of the saccharides having D-galacturonic acid as principal constituent unit and exists in cotton fibers and other numerous plants. Many analytical procedures for these pectic saccharides have been investigated [1] and are applied for various fields such as medicine, biology, botany, etc. In particular, qualitative and quantitative analyses with the colorimetric reaction are widely applied since this reaction has high accuracy and specificity for saccharide.

In our previous paper [2,3], we have reported the hydrolysis of pectic substances present on cotton fabrics with pectinase enzyme in aqueous and in non-aqueous(reverse micellar solution) systems in order to investigate the effect of bio-scouring of cotton fabric. Reverse micelles are known to have a remarkable property to provide an aqueous microenvironment in organic media. Many reports [4-8] have been found stating that enzymes solubilized in the reverse micellar solution showed their enzymatic activity. The microenvironmental provision for enzyme in organic media may be one of the applications of the reverse micellar solution and has been reviewed by Karel et al. [9].

In our previous works concerning the bio-scouring of cotton, we have found that pectic substances on the cotton fabrics were removed effectively as a help of enzyme catalyzed reaction of pectinase when it was treated in the reverse micellar solution compared to that in the aqueous solution. The evaluation of the removability of the pectic substances, however, has been carried out by an indirect method that was based on the decrease in the amount of carboxyl group included in the pectic substances on the cotton fabrics. The direct evaluation based on the measurement of hydrolysis of the pectic substances, i.e., detection of 
produced D-galacturonic acid being the major constituent unit of pectic substance is, therefc desired in order to clarify the activity of pectina $c$ enzyme in reverse micellar system, as well as to clarify the effectiveness of pectinase enzyme on bio-scouring process in organic media.

In this work, we have investigated the colorimetric determination method of D-galacturonic acid in Aerosol-OT/isooctane reverse micellar solution with modifying quantitative methods that have been previously reported [10-16]. In addition, we have also assayed the pectinase catalyzed reaction of pectin in reverse micellar solution as a model of bio-scouring of cotton fabrics in non-aqueous system.

\section{Experimental}

\subsection{Materials}

Sodium bis-2-ethylhexylsulphosuccinate (AerosolOT, AOT) as a surfactant for reverse micelle was obtained from Nacalai Tesque Co., Ltd. Pectinase (aspergillus niger EC3.2.1.15) used in this work was obtained from Tokyo Chemical Industry Co., Ltd. AOT and Pectinase were used without further purification. Naphthoresorcinol (NR) and all other chemicals used were of reagent grade (Nacalai Tesque Co., Ltd.).

\subsection{Method}

\subsubsection{Sample preparation}

AOT reverse micellar solutions were prepared by injecting aqueous stock solution of either buffer alone (0.1 $\mathrm{M} \mathrm{CH}_{3} \mathrm{COOH} / \mathrm{CH}_{3} \mathrm{COONa}, \mathrm{pH} 4$ ), pectinase in buffer, pectin in buffer or D-galacturonic acid in buffer to AOT/isooctane solution. Concentrations of both pectinase and pectin in buffer solution were adjusted so that the overall concentration of enzyme in reverse micellar solution should be $0.033 \mathrm{~g} / \mathrm{L}$. After the injection of aqueous stock solution, the reverse micellar solutions were gently stirred for few minutes until the solutions became transparent. Resultant AOT reverse micellar solutions were categorized by the molar ratio of water to AOT present in the systems, that is, $\mathrm{w}=\left[\mathrm{H}_{2} \mathrm{O}\right] /[\mathrm{AOT}]$. Enzyme reactions were initiated by mixing two reverse micellar solutions, one containing the pectinase and the other containing pectin. The hydrolysis of pectin was carried out at $40^{\circ} \mathrm{C}$ for $0.5-24$ hours. The reaction was stopped by heating the solution at $100{ }^{\circ} \mathrm{C}$ for 30 minutes.

\subsubsection{Coloration procedure}

$\mathrm{NR} /$ water solution was always freshly prepared and was kept in dark during the experiment due to the unstability of NR in water. For the purpose of coloration reaction, $1 \mathrm{~mL}$ of $12 \mathrm{~N} \mathrm{HCl}$ and $1 \mathrm{~mL}$ of $0.2 \%$ (W/V) NR solutions were added to $4 \mathrm{~mL}$ of AOT reverse micellar solution in which the enzymatic hydrolysis of pectin were carried out. The mixtures were then heated in oil bath at $100{ }^{\circ} \mathrm{C}$ for exactly one hour. After the heating process, the mixtures were cooled in cold water bath immediately. The colored products slightly soluble in the reverse micellar solution were completely solubilized with adding $1 \mathrm{~mL}$ of 1-butanol as a co-solvent by vigorous shaking for ca. one minute. The amount of the colored products were determined by spectrophotometry using Shimadzu Double beam spectrophotometer UV-200S.

\section{Results and Discussion}

\subsection{Colorimetric determination method}

Coloration reactions for analysis of saccharides can be roughly classified into two types. The first is the reaction that produces colored compound in the alkaline conditions with aid of the reducing power of saccharides [10-13]. The second is the reaction that produces characteristic colored compound with the condensation reaction between saccharides and a coloring reagent [14-18]. We have examined several reactions for the former type seeking for their optimal conditions. Finally, we have found that D-galacturonic acid showed excellent reducing power and was positive in any reactions examined. Unfortunately, the coloration reaction were also observed in the solution containing only pectinase enzyme even in the absent of saccharides. These facts suggest that the colorimetric determination of D-galacturonic acid due to its reducing power is interfered by the coexisting pectinase enzyme. For the latter type reaction, we have found that the naphthoresorcinol (NR, Tollens reagent) is one of the most promising candidates, reacting the D-galacturonic acid specifically and the reaction was not interfered by any other coexisting substances such as pectinase and pectin. Reaction mechanism of D-galacturonic acid with NR are proposed in early reports [19-21] as shown in Figure 1. The main products (I) and (II), however, were almost insoluble in both 


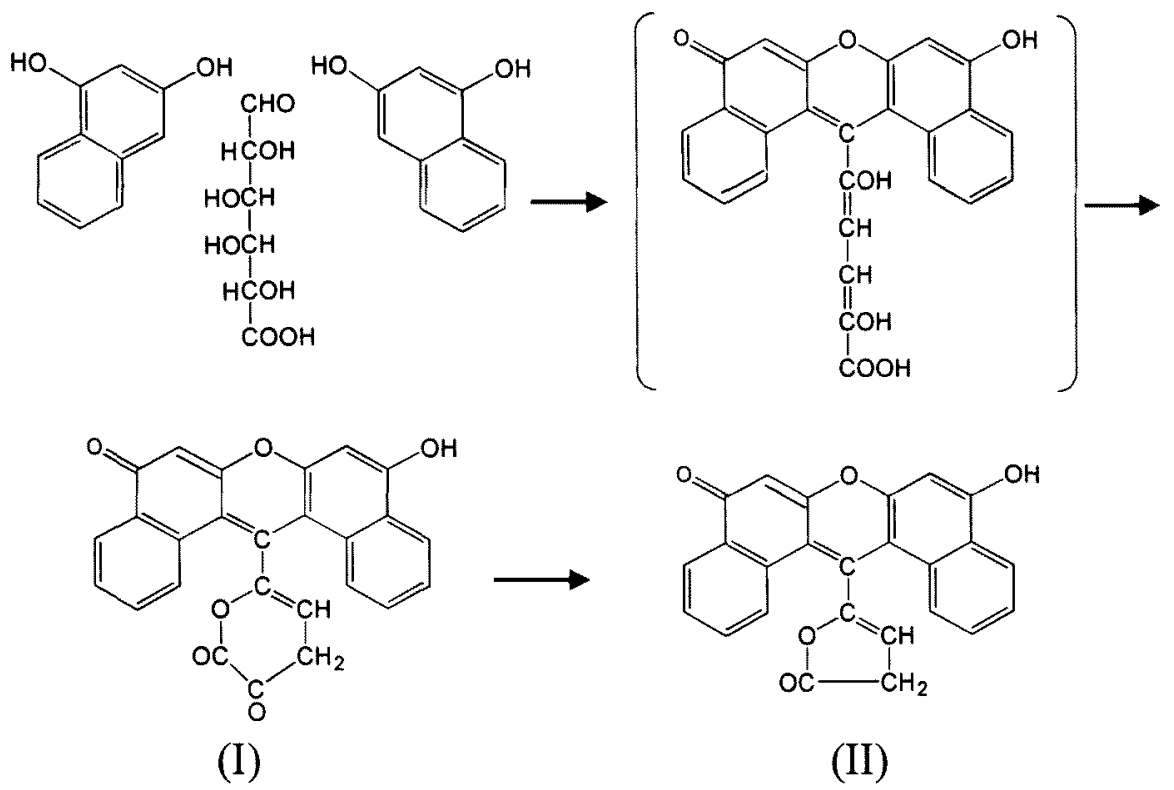

Fig. 1 Reaction scheme of D-galacturonic acid with naphthoresorcinol[19].

aqueous phase and reverse micellar phase, producing the precipitates on the bottom of the reaction vessel. Another solvent that helps to solubilize the colored products in aqueous/reverse micellar mixed solution would, therefore, be necessary in order to determine the amount of D-galacturonic acid with the colorimetric method. Furthermore, the solvent is required to be miscible with either aqueous phase or reverse micellar one as well as not to be miscible with both phases.

In this work, for the purpose of finding out the solvent that satisfies these requirements, we have examined the miscibility of several solvents with two phases and the solubilizing ability for the products (I) and (II) by visual inspection. Results of the properties of the solvents examined in this study were summarized in Table 1, indicating that 1-butanol seems to be the most suitable solvent to solubilize the colored products and is miscible with only organic phase. Figure 2 shows an example of the absorption spectrum of the products in an $0.05 \mathrm{M}$ AOT reverse micellar solution $(w=20) /$ 1-butanol system. As shown in Figure 2, this spectrum has three absorption maxima at 510,580 and $730 \mathrm{~nm}$. The absorptions at 580 and $730 \mathrm{~nm}$ are supposed to occur due to the products derived from $\mathrm{D}$-galacturonic acid. $[14,18,20]$ The absorption at $510 \mathrm{~nm}$ might be induced by the byproducts. In the calibration curves at
Table 1 Solubilizing ability of several organic solvents for the colored product.

\begin{tabular}{|c|c|c|c|}
\hline Solvents & $\begin{array}{l}\text { Solubilizing ability } \\
\text { for product }\end{array}$ & $\begin{array}{l}\text { Miscibility with } \\
\text { aqueous phase }\end{array}$ & $\begin{array}{l}\text { Miscibility with } \\
\text { reverse micellar phase }\end{array}$ \\
\hline ethanol & + & + & + \\
\hline 1.propanol & + & + & + \\
\hline 1-butanol & + & - & + \\
\hline 1-pentanol & \pm & - & + \\
\hline 1.hexanol & \pm & - & + \\
\hline benzyl alcohol & + & - & - \\
\hline cyclohexane & - & - & - \\
\hline toluene & - & - & - \\
\hline
\end{tabular}

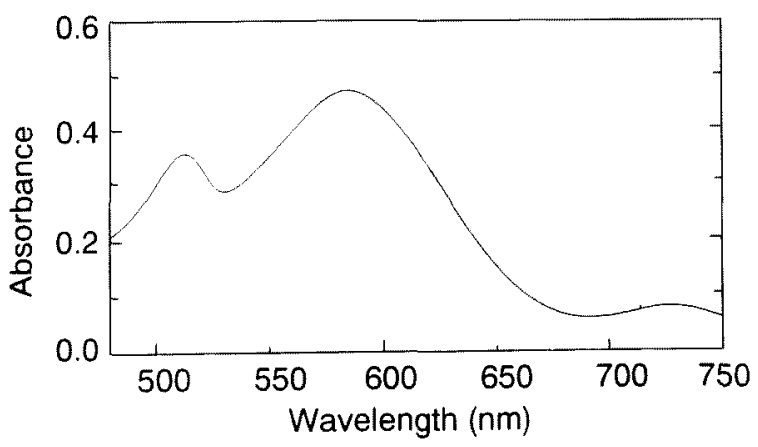

Fig. 2 Absorption spectrum of the colored products in AOT/isooctane/1-butanol solution. 
these wavelength, only the absorption maximum at 580 $\mathrm{nm}$ shows the linearity in the concentration range of D-galacturonic acid used in this study as shown in Figure 3. Similar calibration curves were obtained regardless of the changes of AOT concentration and the amount of solubilized water. These results apparently demonstrate that the enzymatic activity of the pectinase for the hydrolysis of the pectin in reverse micellar solution can be colorimetrically estimated with this method.

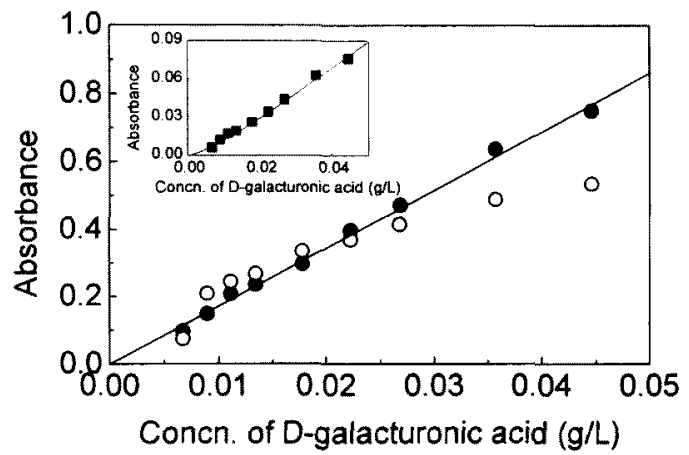

Fig. 3 Calibration curves at $510(0), 580(\bullet)$ and 730 (ם) $\mathrm{nm}$.

As previously reported by Momose et al. [14], the colored products from Tollens reaction are rather unstable in the solution state. The absorbance of the colored products in AOT/isooctane/1-butanol system at $580 \mathrm{~nm}$ was plotted against the elapse of time as shown in Figure 4. The absorbance of the products varies considerably, giving a maximum point around after twenty four hours. These phenomena were also observed in every AOT concentrations and $\mathrm{w}$ ranges.

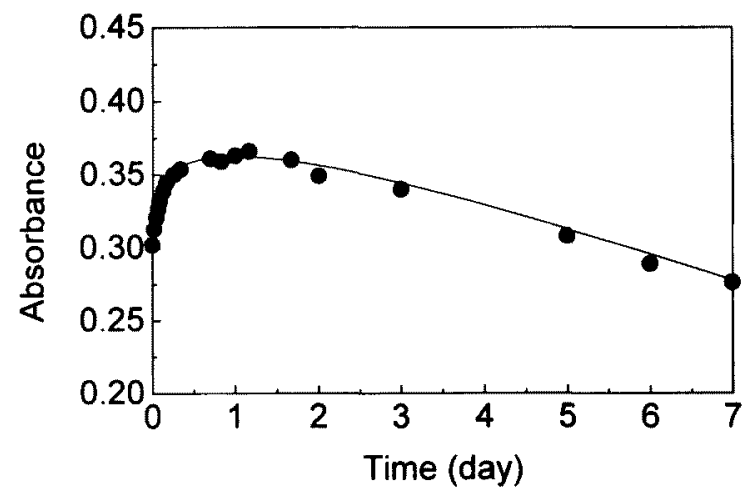

Fig. 4 Variations of the absorbance at $580 \mathrm{~nm}$.
From this result, we have judged that after twenty four hours from the solubilization with 1-butanol is the most appropriate time for the estimating of D-galacturonic acid (major hydrolysis product of pectic substance).

\subsection{Assay of pectinase catalyzed reaction}

Figure 5 shows the result of pectinase catalyzed reaction of pectin in reverse micellar solution measured with optimal experimental conditions described above. As shown in Figure 5, the amount of D-galacturonic acid increases with an increase of the reaction time. These results apparently demonstrate that pectinase solubilized in reverse micellar system has an hydrolyzing activity as has been reported [3]. The influences of the concentration of AOT on the reaction rates are hardly observed and the sufficient activities can be seen in the AOT concentration range as low as $0.025 \mathrm{M}$.

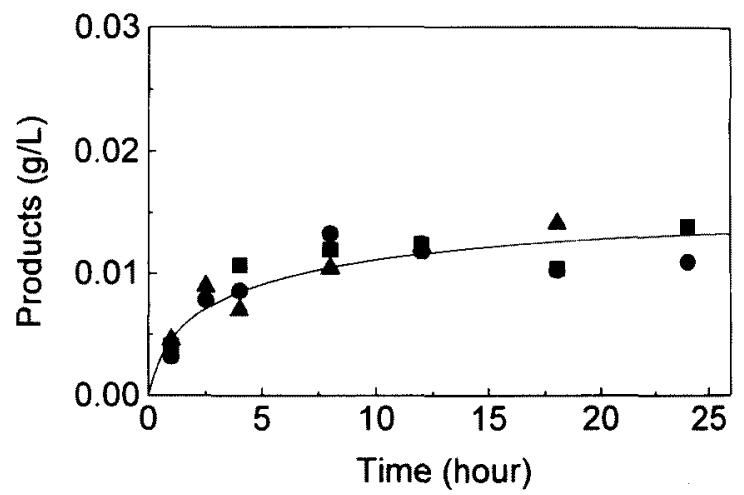

Fig. 5 Pectinase catalyzed hydrolysis of pectin in AOT / isooctane reverse micellar system $(\mathrm{w}=20)$ at $40^{\circ} \mathrm{C}$. Each labeled point designates the concentration of AOT, as follows; $0.025 \mathrm{M}, \mathbf{D}: 0.05 \mathrm{M}, \mathbf{\Delta}: 0.075 \mathrm{M}$.

Furthermore, we have investigated the influences of the amount of solubilized water on the rates of the enzymatic reaction in the same AOT concentration. Figure 6 shows an example of the results in the case of $0.05 \mathrm{M}$ AOT solution. In the case of $\mathrm{w}=15,20$ and 30 , pectinase shows apparent activities though the apparent rates of the enzyme reaction are not wholly equivalent. On the other hand, none of the activities of pectinase are observed for the case of $w=5$ and 10 . In the region of relatively low water contents $(w<10)$, water molecules that were injected in reverse micellar 


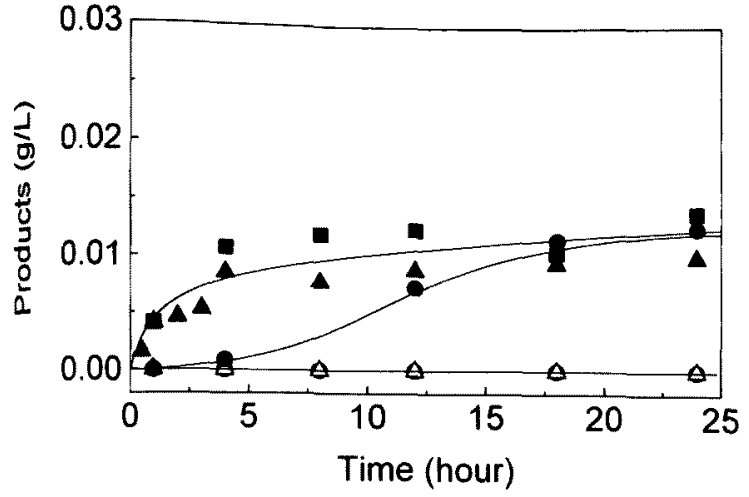

Fig. 6 Pectinase catalyzed hydrolysis of pectin in 0.05 $\mathrm{M} \mathrm{AOT} \mathrm{/} \mathrm{isooctane} \mathrm{reverse} \mathrm{micellar} \mathrm{system} \mathrm{at}$ $40^{\circ} \mathrm{C}$. Each labeled point designates $w$ values, as follows; $\mathrm{O}: 5, \Delta: 10, \mathbf{0}: 15, \mathbf{\mathbf { E }}: 20, \mathbf{\Delta}: 30$.

solution would bound to the ionic head groups of AOT molecule as reported by Kon-no et al. [22] This means that the enzyme accommodated in an inner part of reverse micelles could not exhibit sufficient hydrolytic activity without proper amount of free water. In the region of relatively high water contents $(w>10)$, on the other hand, excess water might exist as free water (or bulk-like water) in the inner part of reverse micelle. Consequently, the environment of the interior of reverse micelles becomes suitable for enzymatic reaction with an increase of the amount of the free water. In this system, threshold value for the solubilized water that is at least necessary for enzymatic reaction seems to be $\mathrm{w}=20$ since the reaction profiles are similar

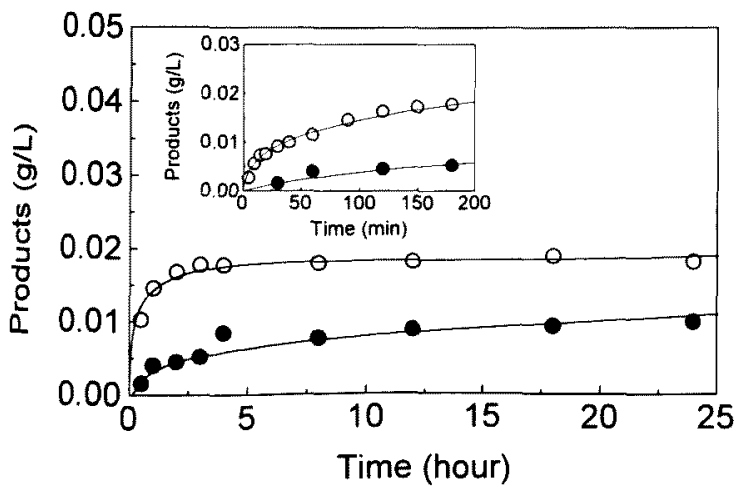

Fig. 7 Comparison of pectinase catalyzed hydrolysis of pectin between in $0.05 \mathrm{M}$ AOT reverse micellar system at $w=30(-)$ and in aqueous system $(O)$. above this w value.

Comparison of the results of enzymatic reaction between in reverse micellar solution and in aqueous one is shown in Figure 7. Rate of the reaction and the ability of hydrolysis of pectin in aqueous system are higher than those in reverse micellar solution, indicating that aqueous microenvironment in the reverse micelles is less favorable for the enzymatic system than in aqueous system. These results obtained in the model reaction studied here, however, are inconsistent with the results of the practical bio-scouring study reported previously [3]. The removal of pectic substances from cotton fabrics with pectinase enzyme in reverse micellar solution has been found to be superior to that in aqueous system. This facts indicate that the degree of the removal of pectic substances from actual cotton fabrics by the bio-scouring process seems not to depend only on the pectinase activities in the system. Extraction of wax and oils on cotton fabrics with organic solvent would help the removal of pectic substances since pectic substances on the cotton fabrics would be covered or be adhered by cotton wax or other substances. This assumptions are satisfactorily supported by the fact that the degree of the removal of pectic substances from cotton fabrics by the bio-scouring process in aqueous system were remarkably increased by the addition of surfactant and organic solvent [2], both which are recognized to help for the removal of cotton wax.

The detail mechanism of the actual hydrolysis of pectic substances in the bio-scouring process can not be fully understood with the limited results of the model study investigated in this work. Further analysis of pectinase catalyzed reaction of pectic substances in reverse micellar system would be necessary.

\section{References}

1. D. Aminoff, W. W. Binkley, R. Schaffer, and R. W. Mowry, "The Carbohydrates Chemistry and Biochemistry", 2nd Ed., Vol. II B, 739, Academic Press.

2. K. Sawada, S. Tokino, and M. Ueda, X. Y. Wang, J. Soc. Dyers Colour., in press.

3. K. Sawada, S. Tokino, and M. Ueda, J. Soc. Dyers Colour., in press.

4. J. W. Shield, H. D. Ferguson, A. S. Bommarius, and 
T. A. Hatton, Ind. Eng. Chem. Fundam., 25, 603 (1986).

5. K. Martinek, A. V. Levashov, N. L. Klyachko, V. I. Pantin, and I. V. Berezin, Biochim. Biophys. Acta, 657, 277(1981).

6. C. Grandi, R. E. Smith, and P. L. Luisi, J. Biol. Chem., 256, 837 (1981).

7. P. D. I. Fletcher, R. B. Freedman, J. Mead, C. Oldfield, and B. H. Robinson, Colloids Surf., 10, 193 (1984).

8. S. Barbaric and P. L. Luisi, J. Am. Chem. Soc., 103, 4239 (1981).

9. M. Karel, V. L. Andrey, K. Nataraya, L. K. Yuri, and V. B. Ilya, Eur. J. Biochem, 155, 453(1986).

10. J. T. Park and M. J. Johnson, J. Biol. Chem., 181, 149 (1949).

11. T. Momose and A. Inaba, Chem. Pharm. Bull., 7, 541 (1959).

12. F. Hostettler, E. Borel, and H. Deuel, Helv. Chim. Acta, 34, 2132(1951).
13. E. Borel and H. Deuel, Helv. Chim. Acta, 36, 801 (1953).

14. T. Momose, Y. Ueda, M. Yoshinaga, J. Masui, and N. Nagasaki, Yakugaku Zasshi, 78, 1064 (1958).

15. T. Bitter and H. M. Muir, Anal. Biochem., 4, 330 (1962).

16. S. Honda, K. Sudo, K. Kakehi, H. Yuki, and K. Takamura, Anal. Chim. Acta, 77, 199(1975).

17. T. Kato and T. Kinoshita, Chem. Pharm. Bull., 26, 1291 (1978).

18. B. Klein and M. Weissman, Anal. Chem., 25, 771 (1953).

19. T. Momose, Y. Ueda, and M. Iwasaki, Pharm. Bull., 4, 49(1956).

20. T. Momose, Y. Ueda, and M. Iwasaki, Chem. Pharm. Bull, 10, 546(1962).

21. T. Momose, Y. Ueda, and M. Iwasaki, Chem. Pharm. Bull., 10, 633 (1962).

22. T. Kawai, K. Hamada, N. Shindo, and K. Kon-no, Bull. Chem. Soc. Jpn., 65, 2715(1992). 